OPEN ACCESS

Edited by:

Qi Chen,

The University of Auckland,

New Zealand

Reviewed by:

Renato Fraietta,

Federal University of São Paulo, Brazil

Ljiljana Marina,

University of Belgrade, Serbia

*Correspondence:

Lisa Owens

l.owens15@imperial.ac.uk

Specialty section:

This article was submitted to

Reproduction,

a section of the journal

Frontiers in Endocrinology

Received: 16 December 2020

Accepted: 15 February 2021

Published: 22 March 2021

Citation:

Phelan N, Behan LA and Owens L (2021) The Impact of the COVID-19

Pandemic on Women's Reproductive Health.

Front. Endocrinol. 12:642755. doi: 10.3389/fendo.2021.642755

\section{The Impact of the COVID-19 Pandemic on Women's Reproductive Health}

\author{
Niamh Phelan ${ }^{1,2}$, Lucy Ann Behan ${ }^{1,3}$ and Lisa Owens ${ }^{1,2 *}$ \\ ${ }^{1}$ Faculty of Health Sciences, School of Medicine, Trinity College Dublin, Dublin, Ireland, 2 Department of Endocrinology, \\ St. James's Hospital, Dublin, Ireland, ${ }^{3}$ Department of Endocrinology, Tallaght University Hospital, Dublin, Ireland
}

Background: The COVID-19 pandemic has profoundly affected the lives of the global population. It is known that periods of stress and psychological distress can affect women's menstrual cycles. We therefore performed an observational study of women's reproductive health over the course of the pandemic thus far.

Materials and Methods: An anonymous digital survey was shared by the authors via social media in September 2020. All women of reproductive age were invited to complete the survey.

Results: 1031 women completed the survey. Mean age was $36.7 \pm 6.6$ years (range, 15 54). 693/70\% reported recording their cycles using an app or diary. 233/23\% were using hormonal contraception. $441 / 46 \%$ reported a change in their menstrual cycle since the beginning of the pandemic. 483/53\% reported worsening premenstrual symptoms, 100/ $18 \%$ reported new menorrhagia $(p=0.003$ ) and $173 / 30 \%$ new dysmenorrhea $(p<$ 0.0001 ) compared to before the pandemic. $72 / 9 \%$ reported missed periods who not previously missed periods ( $\mathrm{p}=0.003$ ) and the median number of missed periods was 2 (1-3). 17/21\% of those who "occasionally" missed periods pre-pandemic missed periods "often" during pandemic. 467/45\% reported a reduced libido. There was no change in the median cycle length (28 days) or days of bleeding (5) but there was a wider variability of cycle length $(p=0.01)$ and a 1 day median decrease in the minimum $(p<0.0001)$ and maximum ( $p=0.009$ ) cycle length. Women reported a median $2 \mathrm{~kg}$ increase in selfreported weight and a 30-min increase in median weekly exercise. 517/50\% of women stated that their diet was worse and $232 / 23 \%$ that it was better than before the pandemic. $407 / 40 \%$ reported working more and 169/16\% were working less. Women related a significant increase in low mood ( $p<0.0001)$, poor appetite $(p<0.0001)$, binge eating $(p<$ $0.0001)$, poor concentration ( $p<0.0001)$, anxiety $(p<0.0001)$, poor sleep $(p<0.0001)$, loneliness $(p<0.0001)$ and excess alcohol use $(p<0.0001)$. Specific stressors reported included work stress (499/48\%), difficulty accessing healthcare (254/25\%), change in financial (201/19\%) situation, difficulties with home schooling (191/19\%) or childcare (99/ $10 \%)$, family or partner conflict (170/16\%), family illness or bereavement (156/15\%). 
Conclusions: The COVID-19 pandemic has significantly impacted the reproductive health of women. The long term health implications of this are yet to be determined and future studies should address this.

Keywords: menstrual abnormalities, COVID-19 pandemic, psychological distress, oligomenorrhea/amenorrhea, libido, dysmenorhea, menorrhagia

\section{INTRODUCTION}

The COVID-19 pandemic, caused by severe acute respiratory syndrome coronavirus 2 (SARS-CoV-2) $(1,2)$, has caused over 106 million infections and 2.3 million deaths worldwide, as of February 2021, according to the WHO COVID-19 Dashboard (3). The virus itself, as well as the measures taken to reduce its spread, have profoundly affected the lives of the global population. The pandemic has significantly impacted the mental health of many people within the population, resulting in loneliness, social isolation, financial strain, as well as the anxiety and fear of contracting the virus, and uncertainty for the future. Analysis of a national, longitudinal cohort study found that by late April 2020, mental health in the UK had deteriorated compared with before the COVID-19 pandemic (4). A US study in April 2020 found higher rates of psychological distress among adults, compared with 2018 (5). In this study the increase in psychological distress was greatest in women and young people aged 18-24 years. On the other hand, there is theoretically a group who have experienced reduced stress and improved mental well-being, for example those with financial security, those who have spent more time with their families and less time commuting since the outbreak of the pandemic.

It is known that periods of stress and psychological distress can affect women's menstrual health. Stressors can activate the hypothalamic-pituitary-gonadal (HPG) axis and can alter the neuro-modulatory cascade that drives gonadotropin releasing hormone $(\mathrm{GnRH})$ regulation (6). This can result in functional hypothalamic amenorrhoea (FHA), chronic anovulation which is not due to an underlying organic cause $(7,8)$. Behavioural modification such as cognitive behavioural therapy can reverse this amenorrhoea (9). FHA also occurs secondary to excessive exercise, dieting and caloric restriction and disordered eating $(10,11)$.

Psychological distress is not only associated with missed periods but also worsening of symptoms associated with menstruation and psychosexual health. Dysmenorrhoea has been shown to be associated with high stress levels (12), emotional instability and depression (13). Pre-menstrual symptoms (PMS) and menorrhagia are also associated with high psychological distress $(14,15)$. Higher perceived stress is also associated with lower libido in women (16).

Our objective therefore was to survey the general female population of reproductive age with regards to their menstrual cycle, libido and changes in their lifestyle over the course of the pandemic thus far. We performed an anonymous observational study by circulating a survey via social media and text message.

\section{MATERIALS AND METHODS}

\section{Study Design}

This was an anonymous observational study. A digital survey was created using the Typeform platform (www.typeform.com). A link to the survey was shared by the authors via social media (Facebook, Twitter) and all women of reproductive age were invited to participate. The survey contained 50 questions on demographic information, menstrual cycle and mental health symptoms, diet, exercise and working patterns from before and since the beginning of the pandemic. It took between 5 and $10 \mathrm{~min}$ to complete. Ethical approval was granted for the study by the St James's and Tallaght University Hospital Research Ethics Committee (JREC 2020-10CA-10). Written consent was not required as all data was collected anonymously. The survey was circulated over a 2-week period in the second half of September 2020. The study was conducted and reported according to published best practice guidelines for reporting observational studies (17). A full list of survey questions can be found in Supplementary Table 1.

\section{Participants}

In total 1031 women completed the survey. All women of reproductive age were invited to participate via digital link. Menstrual cycle and BMI data were excluded from women who became pregnant or delivered a baby during the pandemic. Menstrual cycle data was also excluded from women who stated they were amenorrhoeic for any reason (i.e. due to an intrauterine system, intrauterine device or implant, menopause, breastfeeding).

\section{Statistical Analysis}

Data was analysed using Graphpad Prism version 8.4.3. Parametric data is reported as mean and standard deviation (SD). Non-parametric data is reported as median and interquartile range (IQR). A p-value $<0.05$ was considered statistically significant. A paired t-test was used to compare parametric data for data comparing before and during the pandemic (e.g. comparing dysmenorrhoea experienced before and since the beginning of the pandemic). A Wilcoxon matched pairs rank test was used to compare non-parametric paired data.

\section{RESULTS}

\section{Patient Demographics}

A total of 1031 women completed the survey. The participants demographic information is summarized in Table 1. The mean age of the women was $36.7 \pm 6.6$ years (range, $15-54$ years). The mean self- 
TABLE 1 | Participant demographics/medical history.

\begin{tabular}{|c|c|}
\hline \multicolumn{2}{|l|}{ Demographics } \\
\hline Age (mean $\pm S D)$, years & $36.7 \pm 6.6$ (range, $15-54)$ \\
\hline $\mathrm{BMl}($ mean $\pm \mathrm{SD}), \mathrm{kg} / \mathrm{m}^{2}$ & $25.8 \pm 5.5$ (range, 16.6-65.5) \\
\hline Ethnicity & $\begin{array}{l}\text { 1000/97\% White (White Irish, White British) } \\
\text { 23/2\% Asian } \\
\text { 3/0.3\% Black } \\
\text { 5/0.5\% Other }\end{array}$ \\
\hline Location & $\begin{array}{l}\text { 862/84\% Ireland } \\
\text { 145/14\% UK } \\
\text { 24/2\% other countries }\end{array}$ \\
\hline Marital status & $\begin{array}{l}\text { Single } 249 / 25 \% \\
\text { Married } 567 / 57 \% \\
\text { Cohabiting } 150 / 15 \% \\
\text { Separated/Divorced } 25 / 3 \% \\
\text { Widowed } 1 / 0.1 \%\end{array}$ \\
\hline Occupation & $\begin{array}{l}\text { 301/29\% Healthcare workers (HCW) } \\
\text { 175/17\% Doctors, 57/6\% nurses, 69/7\% } \\
\text { other HCWs }\end{array}$ \\
\hline $\begin{array}{l}\text { Work status and location during } \\
\text { pandemic }\end{array}$ & $\begin{array}{l}\text { Full time in the workplace } 392 / 38 \% \\
\text { Full time from home } 311 / 30 \% \\
\text { Part time in the workplace } 130 / 13 \% \\
\text { Part time from home } 64 / 6 \% \\
\text { Maternity leave } 47 / 5 \% \\
\text { Unemployed before pandemic 56/5\% } \\
\text { Made redundant/unemployed during } \\
\text { pandemic } 23 / 2 \%\end{array}$ \\
\hline Participants with children (yes/no) & $\begin{array}{l}\text { Yes } 593 / 58 \% \\
\text { No } 435 / 42 \%\end{array}$ \\
\hline Currently breastfeeding & $74 / 7.2 \%$ \\
\hline Pre-existing medical conditions & $\begin{array}{l}\text { Polycystic Ovary Syndrome 68/7\% } \\
\text { Excess unwanted hair 308/30\% } \\
\text { Hypothalamic amenorrhoea } 3 / 0.3 \% \\
\text { Endometriosis } 65 / 6 \% \\
\text { Premature ovarian insufficiency } 22 / 2 \% \\
\text { Osteopenia/Osteoporosis } 13 / 1 \% \\
\text { Acne } 115 / 11 \% \\
\text { Thyroid disorder } 91 / 9 \%\end{array}$ \\
\hline Covid-19 history & Yes and tested positive 35/3.4\% \\
\hline "Did you have Covid-19?" & $\begin{array}{l}\text { Yes, had symptoms but did not get tested } \\
63 / 6.1 \% \\
\text { No } 870 / 83 \% \\
\text { No, but had contact with a confirmed case } \\
63 / 6 \%\end{array}$ \\
\hline
\end{tabular}

reported body mass index (BMI) was $25.8 \pm 5.5 \mathrm{~kg} / \mathrm{m}^{2}$. (range, 16.6$65.5 \mathrm{~kg} / \mathrm{m}^{2}$ ). 1000/97\% of the women were of white ethnicity and $1007 / 98 \%$ were based in Ireland or the United Kingdom. 717/72\% were married or cohabiting, 249/25\% were single and 25/3\% were separated or divorced. 593/58\% stated that they had children and 74/ $7.2 \%$ were currently breastfeeding. $897 / 88 \%$ of women were working during the pandemic, $522 / 51 \%$ in the workplace and $375 / 37 \%$ from home. $326 / 59 \%$ of women who had children, home-schooled them when schools were closed and $369 / 66 \%$ had to provide childcare while also trying to work. 301/29\% were healthcare workers (HCW); 175/ 17\% Doctors, $57 / 6 \%$ nurses and 69/7\% were other HCWs. 35/3.4\% stated that they had contracted COVID-19 and tested positive, 63/ $6.1 \%$ had symptoms of COVID-19 but did not get tested.

\section{Menstrual History}

$834 / 81 \%$ of women stated they usually had regular periods. $693 / 70 \%$ of those who had periods recorded them using an app, diary, smartphone or other recording method (Table 2). 747/72\% of
TABLE 2 | Menstrual history and contraceptive use.

\begin{tabular}{|c|c|}
\hline Parameter & Result \\
\hline Contraception use & $\begin{array}{l}\text { None-747/72\% } \\
\text { Combined contraceptive pill/patch- } \\
110 / 11 \% \\
\text { Intrauterine system }-77 / 7 \% \\
\text { Progesterone only pill-31/3\% } \\
\text { Intrauterine device-24/2\% } \\
\text { Implant-13/1\% } \\
\text { Depot-2/0.2\% } \\
\text { Other-27/3\% ( Barrier, tubal ligation, } \\
\text { vasectomy) }\end{array}$ \\
\hline $\begin{array}{l}\text { Cycles recorded using app/diary/ } \\
\text { smartphone/other } \\
\text { Regular periods under normal } \\
\text { circumstances }\end{array}$ & $\begin{array}{l}\text { Yes } 693 / 70 \% \\
\text { No } 297 / 30 \% \\
\text { Yes } 834 / 81 \% \\
\text { No } 163 / 16 \% \\
\text { N/A } 32 / 3 \%\end{array}$ \\
\hline Median cycle length (days) & $28(27-30)$ \\
\hline Median no. of days of bleeding & $5(4-6)$ \\
\hline Minimum length of cycle (days) (median) & $27(25-28)$ \\
\hline $\begin{array}{l}\text { Maximum length of cycle (days) } \\
\text { (median) }\end{array}$ & $30(28-32)$ \\
\hline Missed periods & $\begin{array}{l}\text { 131/13\% (occasionally 82/8\%, often } \\
49 / 5 \% \text { ) }\end{array}$ \\
\hline Heavy periods & $420 / 42 \%$ \\
\hline Painful periods & $416 / 42 \%$ \\
\hline
\end{tabular}

women were not using any form of contraception and 231/22\% were using hormonal contraception (Table 2). The median cycle length was 28 days (27-30) with a 5 day bleed (4-6) and the minimum usual cycle length was 27 (25-28) days and the maximum usual cycle length was 30 days (28-32) (Table 2). 131/ $13 \%$ of women reported missing periods, $82 / 8 \%$ reported missing them occasionally and $49 / 5 \%$ often. $420 / 42 \%$ reported heavy periods and $416 / 42 \%$ painful periods (Table 2).

\section{Menstrual Cycle Changes During the COVID-19 Pandemic}

$441 / 46 \%$ of women who got periods reported an overall change in their menstrual cycle during the COVID-19 pandemic. See Table 3 for menstrual cycle changes. 483/53\% reported a worsening in premenstrual symptoms (PMS), whereas 60/7\% felt that their PMS improved. The median cycle length was 28 days, similar to before the pandemic but with a significantly wider range $(25-30)(\mathrm{p}=0.01) .255 / 29 \%$ noted a reduced cycle length and the median reduction was 3 days (2-6) and $28 \%$ reported a longer cycle with a median increase of 3 days (2-6). The median number of days of bleeding was 5 (4-6) and was unchanged compared to before the pandemic $(\mathrm{p}=0.3)$. The minimum length of the cycle was 26 days (22-28), a median of 1 day shorter than before the pandemic $(\mathrm{p}<0.0001)$. The maximum length of the cycle was 29 days (22-28), also a median of 1 day shorter than before the pandemic $(\mathrm{p}=0.009)$.

$158 / 17 \%$ had missed periods during the pandemic, $4 \% / 27$ more than pre-pandemic ( $\mathrm{p}=0.0003) .72 / 9 \%$ reported new missed periods, of which 56/7\% were "occasional" and 16/2\% were "often." The median number of missed periods was $2(1-3)$. $17 / 21 \%$ who "occasionally" missed periods pre-pandemic missed periods "often" during pandemic. $40 / 31 \%$ of those who had 
TABLE 3 | Menstrual cycle changes during the Covid-19 pandemic.

\begin{tabular}{|c|c|c|}
\hline Change & Result, n/\% & p-value \\
\hline \multirow[t]{2}{*}{ Overall change in menstrual cycle } & Yes-441/46\% & \\
\hline & No $-523 / 54 \%$ & \\
\hline \multirow[t]{3}{*}{ Change in libido/sex drive } & No change $-429 / 42 \%$ & \\
\hline & Increased libido-131/13\% & \\
\hline & Decreased libido-467/45\% & \\
\hline \multirow[t]{3}{*}{ Change in premenstrual symptoms (PMS) } & PMS unchanged-366/40\% & \\
\hline & PMS better - 60/7\% & \\
\hline & PMS worse-483/53\% & \\
\hline \multirow[t]{3}{*}{ Median cycle length (days) } & $28(25-30)$ & 0.01 \\
\hline & $255 / 29 \%$ reduced cycle length -3 days (2-6, range $1-55)$ & \\
\hline & $239 / 28 \%$ increased cycle length +3 days ( $2-6$, range $1-103)$ & \\
\hline No. of days of bleeding (median, IQR) & $5(4-6)$ & $P=0.3$ \\
\hline Minimum length of cycle (days) (median, IQR ) & $26(22-28)$ & $p<0.0001$ \\
\hline Maximum length of cycle (days) (median, IQR) & $29(28-32)$ & $p=0.009$ \\
\hline \multirow[t]{5}{*}{ Missed periods } & $-158 / 17 \%(+4 \% / 27)$ (occasional-93/10\%, often-65/7\%) & $p=0.0003$ \\
\hline & $-72 / 9 \%$ new missed periods (occasional $-56 / 7 \%$, often $-16 / 2 \%$ ) & \\
\hline & -Median missed periods $=2(1-3)$ & \\
\hline & $-17 / 21 \%$ who 'occasionally' missed periods pre-pandemic missed periods 'often' during pandemic & \\
\hline & $-40 / 31 \%$ who had missed periods previously had no missed periods during pandemic & \\
\hline \multirow[t]{3}{*}{ Heavy periods } & $447 / 47 \%$ & $P=0.003$ \\
\hline & $18 \% / 100-$ new heavy periods & \\
\hline & $15 \% / 63-$ less heavy periods & \\
\hline \multirow[t]{3}{*}{ Painful periods } & $469 / 49 \%$ & $p<0.0001$ \\
\hline & $173 / 30 \%$ - new painful periods & \\
\hline & $49 / 12 \%$ - previously painful periods improved & \\
\hline Conceived during pandemic & $84 / 8 \%$ & \\
\hline
\end{tabular}

missed periods previously had no missed periods during pandemic. $467 / 45 \%$ of women reported a decrease in their libido and $131 / 13 \%$ reported an increase in their libido. 447/ $47 \%$ of women reported heavy periods, $27 / 5 \%$ more than before the pandemic ( $p=0.003) .469 / 49 \%$ reported painful periods, $53 /$ $7 \%$ more than before the pandemic $(p<0.0001) .173 / 30 \%$ reported new painful periods and $49 / 12 \%$ reported that previously painful periods improved during the pandemic.

\section{Lifestyle and Mental Health Change During the COVID-19 Pandemic}

The overall median change in self-reported weight was an increase of $2 \mathrm{~kg}(0-4 \mathrm{~kg})(\mathrm{p}<0.0001)$ (Table 4). 622/65\% of women gained weight, and the median weight gain was $3 \mathrm{~kg}(2-5 \mathrm{~kg})$ (Table 4). $158 / 16 \%$ lost weight, and the median weight loss was also $3 \mathrm{~kg}(2-$ $5 \mathrm{~kg}$ ) (Table 4). Women carried out on average 150 (40-270) min of exercise per week during the pandemic, $30 \mathrm{~min}(60-220)$ more than before the pandemic ( $\mathrm{p}=0.02$ ) (Table 4). 517/50\% of women felt that overall their diet was worse during the pandemic. $232 / 23 \%$ felt that their diet overall had improved (Table 4). 127/12\% reported drinking excess alcohol compared to $72 / 7 \%$ before the pandemic (Table 5). $407 / 40 \%$ reported working more than before the pandemic and $169 / 16 \%$ were working less (Table 4).

Women reported a significant increase in suffering from mental health symptoms (Table 5). 868/84\% of women reported suffering from at least one symptom, including low $\operatorname{mood}(519 / 50 \%, \mathrm{p}<$ $0.0001)$, anxiety $(514 / 50 \%, \mathrm{p}<0.0001)$, poor sleep $(509 / 49 \%, \mathrm{p}<$ $0.0001)$, significant stress $(373 / 36 \%, \mathrm{p}<0.0001)$, binge eating (373/ $36 \%, \mathrm{p}<0.0001)$, poor concentration $(373 / 36 \%, \mathrm{p}<0.0001)$,
TABLE 4 | Changes in lifestyle during the COVID-19 pandemic.

\begin{tabular}{|c|c|c|}
\hline Question & Result & $\begin{array}{l}\mathrm{P} \text { - } \\
\text { value }\end{array}$ \\
\hline $\begin{array}{l}\text { Change in weight } \\
(\mathrm{n}=964) \text { (median, IQR) }\end{array}$ & $\begin{array}{l}\text { Median }+2 \mathrm{~kg}(0-4) \\
184 / 19 \% \text { no change in weight } \\
158 / 16 \% \text { lost weight, median }-3 \\
\mathrm{~kg}(2-5 \mathrm{~kg}) \\
622 / 65 \% \text { gained weight, median } \\
+3 \mathrm{~kg}(2-5 \mathrm{~kg})\end{array}$ & $<0.0001$ \\
\hline $\begin{array}{l}\text { Change in minutes of exercise/ } \\
\text { week (median, IQR) }\end{array}$ & $+30(40-270)$ & 0.02 \\
\hline Type of exercise & $\begin{array}{l}\text { Running-350/34\% } \\
\text { Yoga/pilates-300/29\% } \\
\text { HiiT-202/20\% } \\
\text { Strength training-209/20\% } \\
\text { Walking-193/19\% } \\
\text { Other-51/5\% } \\
\text { None-65/6\% }\end{array}$ & \\
\hline Diet & $\begin{array}{l}\text { Overall diet is unchanged-281/ } \\
27 \% \\
\text { Overall diet is better-232/23\% } \\
\text { Overall diet is worse- } 517 / 50 \%\end{array}$ & \\
\hline Change in work practices & $\begin{array}{l}\text { No change }-453 / 44 \% \\
\text { Working more }-407 / 40 \% \\
\text { Working less }-169 / 16 \%\end{array}$ & \\
\hline
\end{tabular}

loneliness (373/36\%, p < 0.0001), poor appetite $(373 / 36 \%$, p < $0.0001)$ and excess alcohol use $(373 / 36 \%, \mathrm{p}<0.0001)$. There was no change in illicit drug use $(1 \%, \mathrm{p}=0.34)$. Women reported experiencing a number of stressors as outlined in Table 6, the most prevalent of which was work stress (499/48\%), followed by difficulties accessing healthcare (254/25\%) (Table 6). 
TABLE 5 | Mental health symptoms.

\begin{tabular}{lccc}
\hline & Before pandemic & During pandemic & P-value \\
\hline Low mood & $359 / 34 \%$ & $519 / 50 \%$ & $<0.0001$ \\
Anxiety & $382 / 37 \%$ & $514 / 50 \%$ & $<0.0001$ \\
Poor sleep & $341 / 33 \%$ & $509 / 49 \%$ & $<0.0001$ \\
Significant stress & $268 / 26 \%$ & $373 / 36 \%$ & $<0.0001$ \\
Binge eating & $236 / 23 \%$ & $335 / 32 \%$ & $<0.0001$ \\
Poor concentration & $172 / 17 \%$ & $360 / 35 \%$ & $<0.0001$ \\
Loneliness & $136 / 13 \%$ & $299 / 29 \%$ & $<0.0001$ \\
Poor appetite & $64 / 6 \%$ & $129 / 12 \%$ & $<0.0001$ \\
Excess alcohol use & $72 / 7 \%$ & $127 / 12 \%$ & $<0.0001$ \\
Illicit drug use & $11 / 1 \%$ & $7 / 1 \%$ & 0.34 \\
\hline
\end{tabular}

TABLE 6 | Stressors. "Have you had any of the following stressors over the course of the pandemic?"

\begin{tabular}{lc}
\hline Stressor & $\mathbf{n} / \%$ \\
\hline Work stress or change in employment status & $499 / 48 \%$ \\
Difficulties accessing healthcare & $254 / 25 \%$ \\
Change in financial situation & $201 / 19 \%$ \\
Difficulties with home schooling & $191 / 19 \%$ \\
Family illness or bereavement & $169 / 16 \%$ \\
Change in living situation & $156 / 15 \%$ \\
Family or partner conflict & $170 / 16 \%$ \\
Difficulties providing or arranging childcare & $99 / 10 \%$ \\
\hline
\end{tabular}

Women who reported experiencing one or more of low mood, anxiety, or significant stress were significantly more likely to report an overall change in their menstrual cycles since the beginning of the pandemic (50\% versus $34 \%, \mathrm{p}<0.0001$ ). These women with mental health symptoms were also more likely to report painful periods (54\% versus $36 \%, \mathrm{p}<0.0001$ ), worsening pre-menstrual symptoms ( $62 \%$ versus $32 \%, \mathrm{p}<0.0001$ ), as well as decreased libido (51\% versus $31 \%, \mathrm{p}<0.0001) .18 \%$ of women who experienced low mood, anxiety, and/or significant stress reported missing periods since the beginning of the pandemic, whereas $13 \%$ of those who did not experience these mental health symptoms reported missed periods, however this difference was not significant $(\mathrm{p}=0.08)$. Those women who reported an overall change in their menstrual cycles were more likely to have reported poor sleep (41\%) than those who did not report a change in their menstrual cycles $(28 \%), \mathrm{p}<0.0001$.

The final question of the study asked "do you have any other comments related to the impact of COVID-19 pandemic on your life?" $420 / 41 \%$ of respondents added a comment. Selections of the responses are provided in Supplementary Table 2. We labelled the comments as "positive," "negative," "mixed" or "neutral" depending on what impact was described by the respondents. $322 / 77 \%$ of comments described a negative impact of the pandemic on their lives, $41 / 10 \%$ described an overall positive impact of the pandemic, $27 / 6 \%$ commented that the pandemic had both positive and negative impacts on their lives, and $30 / 7 \%$ of comments were neutral.

\section{DISCUSSION}

This large, anonymous observational study has demonstrated that a large proportion of the female population have experienced reproductive health disturbance as a result of the COVID-19 pandemic. These disturbances are associated with a significant increase in suffering from mental health symptoms, as well as weight gain, longer working hours and an unhealthier diet. A minority of women have described improvement in their reproductive health and lifestyle over the course of the pandemic.

Women reported disturbances in their menstrual cycles that are known to be associated with psychological distress. Stress has an inhibitory effect on the hypothalamic pituitary gonadal axis (HPG). Stress and stress hormones inhibit GnRH release from the hypothalamus, and glucocorticoids inhibit luteinising hormone $(\mathrm{LH})$ release and oestrogen and progesterone production by the ovary $(18,19)$. Stress regulates HPG axis through activation of hypothalamic sympathetic neural pathways that result in norepinephrine release in the ovary (20).

Functional hypothalamic amenorrhoea (FHA), chronic anovulation which is not due to an underlying organic cause, is associated with vigorous excess and an energy deficit, as well as stress, anxiety and mood disorders $(7,8,21,22)$. FHA has long-term health consequences including subfertility, osteoporosis, increased risk of cardiovascular disease and psychiatric disease (23). There was a significant increase in missed periods, likely as a result of psychological distress and an increase in the amount of exercise being carried out. Whether these missed periods will ultimately progress to chronic anovulation is as yet unknown. Women who missed periods occasionally before the pandemic reported missing them often during the pandemic. Given that many women gained weight and reported that their diet had worsened, this amenorrhoea is likely related to not only stress related amenorrhoea, but also overweight/obesity and worsening of PCOS symptoms, both known to be affected by incremental increases in weight $(24,25)$.

Over half of respondents reported worsening symptoms of pre-menstrual syndrome (PMS). Studies have demonstrated a higher prevalence of PMS among women with a high psychosocial stress level (15). PMS can have a significant impact on women's health and is associated with impairment of activities of daily living and mental health disorders such as anxiety disorders, postnatal and perimenopausal depression (26). Almost half of women reported periods that were heavy and painful, a significant increase compared to before the pandemic. Again this is largely unsurprising as both have been shown to be associated with stress, psychological distress and low mood (1215). $45 \%$ of women also reported a reduction in their libido. Hypoactive sexual desire disorder, when symptoms persist for over 6 months and are accompanied by distress, affects $6 \%$ to $13 \%$ of the European adult female population $(27,28)$. Selfreported reduced sexual desire has been shown to be associated with lower quality of life, poor self-esteem and hopelessness, as well as depression and anxiety (27).

Women reported no change in the median length of their cycle but there was a significantly wider range in the length of their cycle and a shortening of the minimum and maximum cycle length recorded. It is known that for those trying to conceive, shorter or longer menstrual cycles are less likely to be ovulatory and be followed by conception and are more likely to end in spontaneous abortion (29). 
There was a significant increase in reported acute mental health suffering since the outbreak of the pandemic. Approximately half reported low mood and anxiety and approximately one third reported stress, binge eating, poor concentration and loneliness. Those who experienced low mood, anxiety and/or significant stress were more likely to report an overall change in their menstrual cycle, as well as worsening pre-menstrual symptoms, more painful periods, and reduced libido. Almost half of women reported poor sleep, and those who reported poor sleep were more likely to have experienced alteration in their menstrual cycle. It is known that sex hormones influence circadian rhythm, and vice versa $(30,31)$. PMS, which increased during the pandemic, is also associated with sleep disturbance (32). Sleep disturbance may actually affect fertility, as it has found to be more prevalent in those with infertility and those with diminished ovarian reserve (33).

Women also recorded lifestyle changes which may have impacted their menstrual cycles. There was an overall increase in the amount of exercise being undertaken, by half an hour per week. Despite this women gained weight, a median of $2 \mathrm{~kg}$, likely because half of the women reported that their diet was worse and almost one third reported binge eating since the beginning of the pandemic. $40 \%$ of women were also working more during the pandemic, which would limit the time available for preparing healthy meals.

While a significant proportion of women described the negative impact of the pandemic on their menstrual cycle and lifestyle, there was a minority who described a positive effect. Some women had noted more regular periods, and periods that were less heavy and painful with less PMS. Some women reported an increase in their libido. There was an increase in average exercise per week, and 1 in 6 women lost weight. When they were invited to comment about the impact of the COVID-19 pandemic one in ten women described positive aspects of the pandemic; including a slower pace of life, less commuting and getting to spend more time with their families. Some women (6\%) recognised both a positive and negative impact of the pandemic on their lives. It is as yet impossible to know if any positive effects will endure as the pandemic continues and progresses.

The major strength of this study is the large number of women surveyed, as well as the novel nature of the data. Another strength of the study is the fact that the majority (70\%) of women were recording their menstrual cycle pattern using diary or smartphone app, therefore the menstrual cycle data is likely to be largely unbiased. In addition, the survey was anonymous, reducing the effect of social desirability bias, where people are more likely to report experiences that are considered to be socially acceptable.

There are several limitations to this observational study. The first is that the study recorded self-reported data, which is subject to bias. Self-reporting of menstrual cycle has been shown to have measurement error (34). However the majority of women in our study were recording their cycles using an app or a diary, reducing recall bias. Self-reported weight can also be inaccurate, however a study showed that when young people self-report weight they under-estimate by an average of only $0.4 \mathrm{~kg}$ (35), a modest under-estimate. In addition the mean BMI was $25.8 \mathrm{~kg} / \mathrm{m}^{2}$, similar to previous large studies in women of reproductive age (36). Another potential limitation is that there may have been sampling bias, where those who opted to complete the survey were those who were more likely to have suffered menstrual disturbance. While we acknowledge that selfreported data collection is subject to bias, using digital surveys is a safe way to perform research during the pandemic, and given the anonymous nature of the study, the results have merit and provide a valuable insight into reproductive disturbances women have experienced as a result of the pandemic.

Another limitation is the population of women that completed the survey. The majority were of white ethnic background, so the data may not be representative of all women. The pandemic has disproportionately affected certain sectors of society, such as women of black, Asian or minority ethnic (BAME) background, who are more likely to be severely affected if they contract COVID-19 (37) and more likely to be from lower socio-economic backgrounds (38). $88 \%$ of respondents were in employment, which is higher than the European Union average for women of $66.5 \%$ (39). The average age was 36 , and it is known younger women are more likely to develop hypothalamic amenorrhoea (40), so it is possible that a younger cohort of women may have worse symptoms. There was also a high number of healthcare workers surveyed, who may be more significantly affected by the pandemic due to enhanced workplace stressors and fear of exposure to COVID-19. Lastly, the reported mental health symptoms were intended only to provide a snapshot of how women were feeling subjectively, and are not an objective, qualitative measure of symptoms using validated mental health questionnaires. The main focus of this study was on the reproductive symptoms women were experiencing.

While it is clear from this study that women have suffered significant reproductive health disruption since the beginning of the pandemic, the medium and long term impacts of this are, as yet, unknown. This study captured the first approximately 6 months of the pandemic (February/March 2020 to September 2020). The longer term health implications are likely to also depend on the duration of the pandemic and other uncertainties such as the economic impact and the distribution of and access to COVID-19 vaccines. Future work should include continued multi-modal assessment at different intervals over the course of the pandemic, including ongoing validated assessment of mental health and measurements of BMI, hormone levels and ovulation.

\section{DATA AVAILABILITY STATEMENT}

The raw data supporting the conclusions of this article will be made available by the authors, without undue reservation.

\section{ETHICS STATEMENT}

The studies involving human participants were reviewed and approved by St James's and Tallaght University Hospitals REC. 
Written informed consent for participation was not required for this study in accordance with the national legislation and the institutional requirements.

\section{AUTHOR CONTRIBUTIONS}

LO is the primary investigator and completed data analysis and wrote the manuscript. NP wrote the manuscript and was involved in setting up and completing the study. LB wrote the manuscript and was involved in setting up and completing the study. All authors contributed to the article and approved the submitted version.

\section{REFERENCES}

1. Chan JF, Yuan S, Kok KH, To KK, Chu H, Yang J, et al. A familial cluster of pneumonia associated with the 2019 novel coronavirus indicating person-toperson transmission: a study of a family cluster. Lancet (2020) 395(10223):514-23. doi: 10.1016/S0140-6736(20)30154-9

2. Chen N, Zhou M, Dong X, Qu J, Gong F, Han Y, et al. Epidemiological and clinical characteristics of 99 cases of 2019 novel coronavirus pneumonia in Wuhan, China: a descriptive study. Lancet (2020) 395(10223):507-13. doi: 10.1016/S0140-6736(20)30211-7

3. Organisation, W.H. WHO Coronavirus Disease (COVID-19) Dashboard. (2020). Available at: https://covid19.who.int

4. Pierce M, Hope H, Ford T, Hatch S, Hotopf M, John A, et al. Mental health before and during the COVID-19 pandemic: a longitudinal probability sample survey of the UK population. Lancet Psychiatry (2020) 7(10):88392. doi: 10.1016/S2215-0366(20)30308-4

5. McGinty EE, Presskreischer R, Han H, Barry CL. Psychological Distress and Loneliness Reported by US Adults in 2018 and April 2020. JAMA (2020) 324 (1):93-4. doi: 10.1001/jama.2020.9740

6. Williams NI, Berga SL, Cameron JL. Synergism between psychosocial and metabolic stressors: impact on reproductive function in cynomolgus monkeys. Am J Physiol Endocrinol Metab (2007) 293(1):E270-6. doi: 10.1152/ajpendo.00108.2007

7. Berga SL, Girton LG. The psychoneuroendocrinology of functional hypothalamic amenorrhea. Psychiatr Clin North Am (1989) 12(1):105-16. doi: 10.1016/S0193-953X(18)30454-4

8. Giles DE, Berga SL. Cognitive and psychiatric correlates of functional hypothalamic amenorrhea: a controlled comparison. Fertil Steril (1993) 60 (3):486-92. doi: 10.1016/S0015-0282(16)56165-2

9. Berga SL, Loucks TL. Use of cognitive behavior therapy for functional hypothalamic amenorrhea. Ann N Y Acad Sci (2006) 1092:114-29. doi: 10.1196/annals.1365.010

10. Laughlin GA, Dominguez CE, Yen SS. Nutritional and endocrine-metabolic aberrations in women with functional hypothalamic amenorrhea. J Clin Endocrinol Metab (1998) 83(1):25-32. doi: 10.1210/jc.83.1.25

11. Benson JE, Engelbert-Fenton KA, Eisenman PA. Nutritional aspects of amenorrhea in the female athlete triad. Int J Sport Nutr (1996) 6(2):134-45. doi: 10.1123/ijsn.6.2.134

12. Abu Helwa HA, Mitaeb AA, Al-Hamshri S, Sweileh WM. Prevalence of dysmenorrhea and predictors of its pain intensity among Palestinian female university students. BMC Womens Health (2018) 18(1):18. doi: 10.1186/ s12905-018-0516-1

13. Ibrahim NK, AlGhamdi MS, Al-Shaibani AN, AlAmri FA, Alharbi HA, AlJadani AK, et al. Dysmenorrhea among female medical students in King Abdulaziz University: Prevalence, Predictors and outcome. Pak J Med Sci (2015) 31(6):1312-7. doi: 10.12669/pjms.316.8752

14. Morales-Carmona F, Pimentel-Nieto D, Bustos-López H. [Menstrual cycle perception and psychological distress in a sample of Mexican women]. Rev Invest Clin (2008) 60(6):478-85.

15. Warner P, Bancroft J. Factors related to self-reporting of the pre-menstrual syndrome. Br J Psychiatry (1990) 157:249-60. doi: 10.1192/bjp.157.2.249

\section{ACKNOWLEDGMENTS}

The authors would like to acknowledge the women who kindly gave of their time and completed the survey, and the PMGUK Facebook group who completed and shared the survey.

\section{SUPPLEMENTARY MATERIAL}

The Supplementary Material for this article can be found online at: https://www.frontiersin.org/articles/10.3389/fendo.2021. 642755/full\#supplementary-material

16. Raisanen JC, Chadwick SB, Michalak N, van Anders SM, et al. Average Associations Between Sexual Desire, Testosterone, and Stress in Women and Men Over Time. Arch Sex Behav (2018) 47(6):1613-31. doi: 10.1007/s10508-0181231-6

17. von Elm E, Altman DG, Egger M, Pocock SJ, Gøtzsche PC, Vandenbroucke JP, et al. The Strengthening the Reporting of Observational Studies in Epidemiology (STROBE) statement: guidelines for reporting observational studies. J Clin Epidemiol (2008) 61(4):344-9. doi: 10.1016/j.jclinepi.2007.11.008

18. Toufexis D, Rivarola MA, Lara H, Viau V. Stress and the reproductive axis. J Neuroendocrinol (2014) 26(9):573-86. doi: 10.1111/jne.12179

19. Chrousos GP, Torpy DJ, Gold PW. Interactions between the hypothalamicpituitary-adrenal axis and the female reproductive system: clinical implications. Ann Intern Med (1998) 129(3):229-40. doi: 10.7326/0003-4819-129-3-19980801000012

20. Mayerhofer A, Dissen GA, Costa ME, Ojeda SR. A role for neurotransmitters in early follicular development: induction of functional follicle-stimulating hormone receptors in newly formed follicles of the rat ovary. Endocrinology (1997) 138(8):3320-9. doi: 10.1210/endo.138.8.5335

21. Navarro VM, Kaiser UB. Metabolic influences on neuroendocrine regulation of reproduction. Curr Opin Endocrinol Diabetes Obes (2013) 20(4):335-41. doi: 10.1097/MED.0b013e32836318ce

22. Villanueva AL, Schlosser C, Hopper B, Liu JH, Hoffman DI, Rebar RW. Increased cortisol production in women runners. J Clin Endocrinol Metab (1986) 63(1):133-6. doi: 10.1210/jcem-63-1-133

23. Gordon CM, Ackerman KE, Berga SL, Kaplan JR, Mastorakos G, Misra M, et al. Functional Hypothalamic Amenorrhea: An Endocrine Society Clinical Practice Guideline. J Clin Endocrinol Metab (2017) 102(5):1413-39. doi: 10.1210/jc.2017-00131

24. De Pergola G, Tartagni M, d'Angelo F, Centoducati C, Guida P, Giorgino R. Abdominal fat accumulation, and not insulin resistance, is associated to oligomenorrhea in non-hyperandrogenic overweight/obese women. J Endocrinol Invest (2009) 32(2):98-101. doi: 10.1007/BF03345694

25. Lim SS, Norman RJ, Davies MJ, Moran LJ. The effect of obesity on polycystic ovary syndrome: a systematic review and meta-analysis. Obes Rev (2013) 14 (2):95-109. doi: 10.1111/j.1467-789X.2012.01053.x

26. Yonkers KA, O’Brien PM, Eriksson E. Premenstrual syndrome. Lancet (2008) 371(9619):1200-10. doi: 10.1016/S0140-6736(08)60527-9

27. Goldstein I, Kim NN, Clayton AH, DeRogatis LR, Giraldi A, Parish SJ, et al. Hypoactive Sexual Desire Disorder: International Society for the Study of Women's Sexual Health (ISSWSH) Expert Consensus Panel Review. Mayo Clin Proc (2017) 92(1):114-28.

28. Hayes RD, Dennerstein L, Bennett CM, Koochaki PE, Leiblum SR, Graziottin A. Relationship between hypoactive sexual desire disorder and aging. Fertil Steril (2007) 87(1):107-12. doi: 10.1016/j.fertnstert.2006.05.071

29. Small CM, Manatunga AK, Klein M, Feigelson HS, Dominguez CE, McChesney R, et al. Menstrual cycle characteristics: associations with fertility and spontaneous abortion. Epidemiology (2006) 17(1):52-60. doi: 10.1097/01.ede.0000190540.95748.e6

30. Rahman SA, Grant LK, Gooley JJ, Rajaratnam SMW, Czeisler CA, Lockley SW, et al. Endogenous Circadian Regulation of Female Reproductive 
Hormones. J Clin Endocrinol Metab (2019) 104(12):6049-59. doi: 10.1210/ jc.2019-00803

31. Shechter A, Boivin DB. Sleep, Hormones, and Circadian Rhythms throughout the Menstrual Cycle in Healthy Women and Women with Premenstrual Dysphoric Disorder. Int J Endocrinol (2010) 2010:259345. doi: 10.1155/2010/259345

32. Jehan S, Auguste E, Hussain M, Pandi-Perumal SR, Brzezinski A, Gupta R, et al. Sleep and Premenstrual Syndrome. J Sleep Med Disord (2016) 3(5).

33. Pal L, Bevilacqua K, Zeitlian G, Shu J, Santoro N. Implications of diminished ovarian reserve (DOR) extend well beyond reproductive concerns. Menopause (2008) 15(6):1086-94. doi: 10.1097/gme.0b013e3181728467

34. Small CM, Manatunga AK, Marcus M. Validity of self-reported menstrual cycle length. Ann Epidemiol (2007) 17(3):163-70. doi: 10.1016/j.annepidem.2006.05.005

35. Nikolaou CK, Hankey CR, Lean MEJ. Accuracy of on-line self-reported weights and heights by young adults. Eur J Public Health (2017) 27(5):898903. doi: 10.1093/eurpub/ckx077

36. McKeating A, Maguire PJ, Daly N, Farren M, McMahon L, Turner MJ. Trends in maternal obesity in a large university hospital 2009-2013. Acta Obstet Gynecol Scand (2015) 94(9):969-75. doi: 10.1111/aogs.12685

37. Pan D, Sze S, Minhas JS, Bangash MN, Pareek N, Divall P, et al. The impact of ethnicity on clinical outcomes in COVID-19: A systematic review. EClinicalMedicine (2020) 23:100404. doi: 10.1016/j.eclinm.2020.100404
38. Ministry of Housing, C.a.L.G.U. English indices of deprivation 2019. (2020). Availabe at: https://assets.publishing.service.gov.uk/government/uploads/system/ uploads/attachment_data/file/835115/IoD2019_Statistical_Release.pdf

39. Eurostat. Gender statistics. (2020). Available at: https://ec.europa.eu/ eurostat/statisticsexplained/index.php/Gender_statistics\#Earningshttps:// ec.europa.eu/eurostat/statisticsexplained/index.php/Gender_statistics \#Earnings

40. Falsetti L, Gambera A, Barbetti L, Specchia C. Long-term follow-up of functional hypothalamic amenorrhea and prognostic factors. J Clin Endocrinol Metab (2002) 87(2):500-5. doi: 10.1210/jcem.87.2.8195

Conflict of Interest: The authors declare that the research was conducted in the absence of any commercial or financial relationships that could be construed as a potential conflict of interest.

Copyright (๑) 2021 Phelan, Behan and Owens. This is an open-access article distributed under the terms of the Creative Commons Attribution License (CC BY). The use, distribution or reproduction in other forums is permitted, provided the original author(s) and the copyright owner(s) are credited and that the original publication in this journal is cited, in accordance with accepted academic practice. No use, distribution or reproduction is permitted which does not comply with these terms. 